\title{
Rehabilitation in left distal femoral varus osteotomy and left knee arthroscopy by gonarthrosis grade III: 4 phase model. About a case
}

\section{Rehabilitación en artroscopia de rodilla izquierda y osteotomía varizante de fémur distal izquierdo por gonartrosis grado III: modelo de 4 fases. A propósito de un caso}

\author{
PÉREZ-ÁNGELES, José Manuel
}

ID $1^{\text {st }}$ Author: José Manuel, Pérez-Ángeles / ID: 0018 (2020)

\begin{abstract}
Objective: describing the evolution of rehabilitation in a 47-year-old patient operated on knee arthroscopy and varus osteotomy of the left distal femur due to grade III gonarthrosis secondary to valgus angular disease, she underwent both surgical procedures in a single time. This fact allows a single rehabilitation process to be carried out for the 2 diseases, achieving an earlier functional recovery that if it had been operated in 2 times.
\end{abstract}

Knee, Osteotomy, Arthrosis, Pain, Rehabilitation

\section{Resumen}

Objetivo: describir la evolución de rehabilitación en una paciente operada de artroscopia de rodilla y osteotomía varizante de fémur distal izquierdo por gonartrosis grado III secundario a enfermedad angular en valgo. Fue sometida a ambos procedimientos quirúrgicos en un solo tiempo. Este hecho permite realizar un único proceso de rehabilitación para las 2 enfermedades, consiguiendo una recuperación funcional más temprana que si se hubiera intervenido en 2 tiempos.

Rodilla, Osteotomía, Artrosis, Dolor, Rehabilitación

Citation: PÉREZ-ÁNGELES, José Manuel. Rehabilitation in left distal femoral varus osteotomy and left knee arthroscopy by gonarthrosis grade III: 4 phase model. About a case. Journal of Technological Prototypes. 2020. 6-17: 22-31.

$\dagger$ Researcher contributing first author 


\section{Introduction}

Gonarthrosis is considered as one of the diseases that most frequently cause a significant social, economic and health impact. It represents a degenerative process that affects one or more of the compartments that this joint represents. The cause is still unknown. It occurs late in life, clinically manifests with pain, deformity and limitation of joint movement. The changes in the articular hyaline cartilage are considerable, the subchondral bone becomes sclerosed and forms marginal osteophytes. According to the EPISER study, a prevalence of symptomatic gonarthrosis in the population older than 20 years of $10.2 \%$ was detected in 300 autopsies, being $33.7 \%$ in people older than 70 years. It occurs in women more frequently than in men (2.4: 1 respectively) [1].

The clinical practice guidelines consider non-pharmacological measures as the initial intervention, and form the fundamental pillar, being therapeutic exercise and patient education as important measures [2].

As part of the treatment, the pharmacological type is divided into two groups: a) symptom modifying drugs, aimed at controlling pain, and b) structure modifying drugs, aimed at preserving the articular cartilage, as well as slowing down the evolution of the disease [3].

Non-pharmacological interventions or measures are the cornerstone of osteoarthritis intervention strategies. A biopsychosocial approach should be carried out in an assessment of the arthrosic patient: assessment of physical condition, daily activities, educational needs and motivation for self-care [4].
There is evidence in favor that the selfcare program reduces healthcare costs, decreases the number of admissions to hospitalization and emergency consultations, promoting an improvement in the doctorpatient relationship. Self-care support is carried out in multiple ways: consideration of problems from the patient's point of view, providing selfcare education in group or individual sessions, etc [5].

When conservative treatment is not successful, surgical treatment is necessary. This treatment is reserved for cases in which other minor therapies have failed. The objective of the surgery is to reduce pain and improve joint functionality; For this, different surgical techniques are used in order to preserve or restore joint surfaces, replace joints with artificial implants and fuse joints (arthrodesis).

Osteotomy is a treatment of choice in patients under 50 years of age for knee osteoarthritis. In 2002, Kanamiya6 et al. Reported the benefits of this procedure in the regeneration of cartilage in the medial compartment after surgery.

There is a little written on rehabilitative treatment in distal femoral varus osteotomy concomitant with arthroscopic treatment in the context of previous symptomatic gonarthrosis. In the scientific literature, an infinite number of descriptions and studies on the treatment of this pathology can be found with the postoperative period of total knee arthroplasty and knee arthroscopy, but no clinical case has been found describing the rehabilitation evolution in a patient with a postoperative osteotomy on knee. The case presented, age, previous osteoarthritis, occupation and comorbidities of the patient made it possible to propose a unique intervention for rehabilitative treatment, this shortening the rehabilitation time and achieving an earlier functional recovery.

PÉREZ-ÁNGELES, José Manuel. Rehabilitation in left distal femoral varus osteotomy and left knee arthroscopy by gonarthrosis grade III: 4 phase model. About a case. Journal of Technological Prototypes. 2020 


\section{Clinical case}

This is a 47-year-old female patient, weighing 171.96 pounds and $5.24 \mathrm{ft}$ tall, a housewife, with no significant history, who began her current long-term illness with a predominance of pain and functional impotence in the knee. left that exacerbated household activities. She goes to her family medicine unit, where she is sent to a well-known orthopedic hospital in the city of Puebla, where she is diagnosed with Kellgreen \& Lawrence III left knee gonarthrosis. On physical examination, the patient presented a unilateral valgus deformity, with limitation to active knee mobility caused by pain at $90^{\circ}$ flexion. No motor deficit was observed. The ambulation of this patient was precarious, she did not need accessories for walking.

In the radiological study (Fig. 1), a decrease in the joint space was observed, predominantly in the medial compartment, with the presence of subchondral sclerosis and decreased patellofemoral space. 


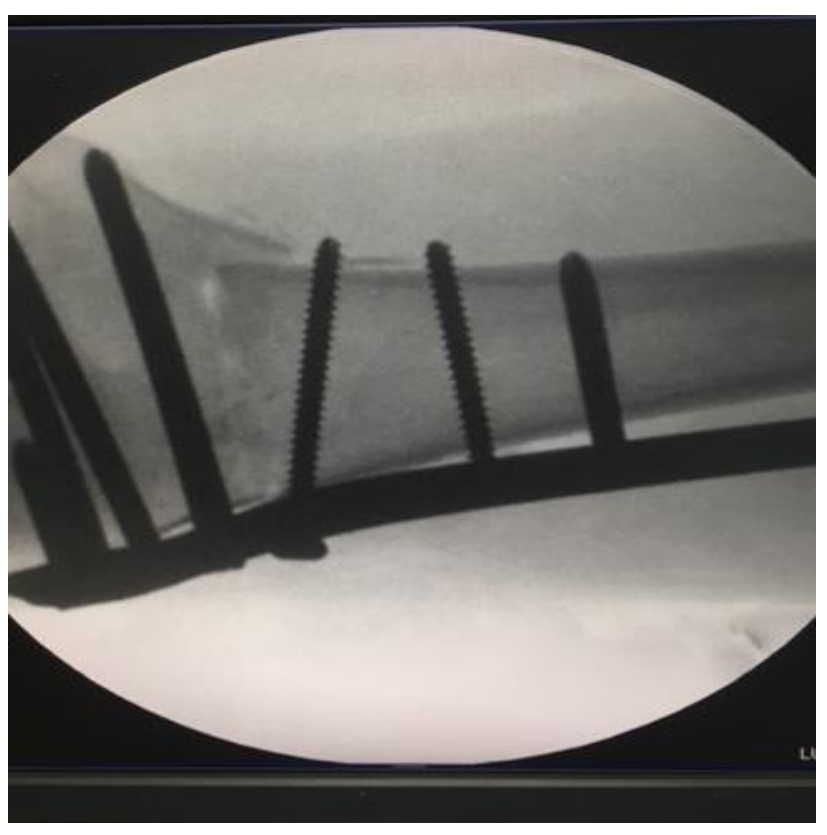

Figure 2 Flouroscopic control. Final result at the end of the surgery

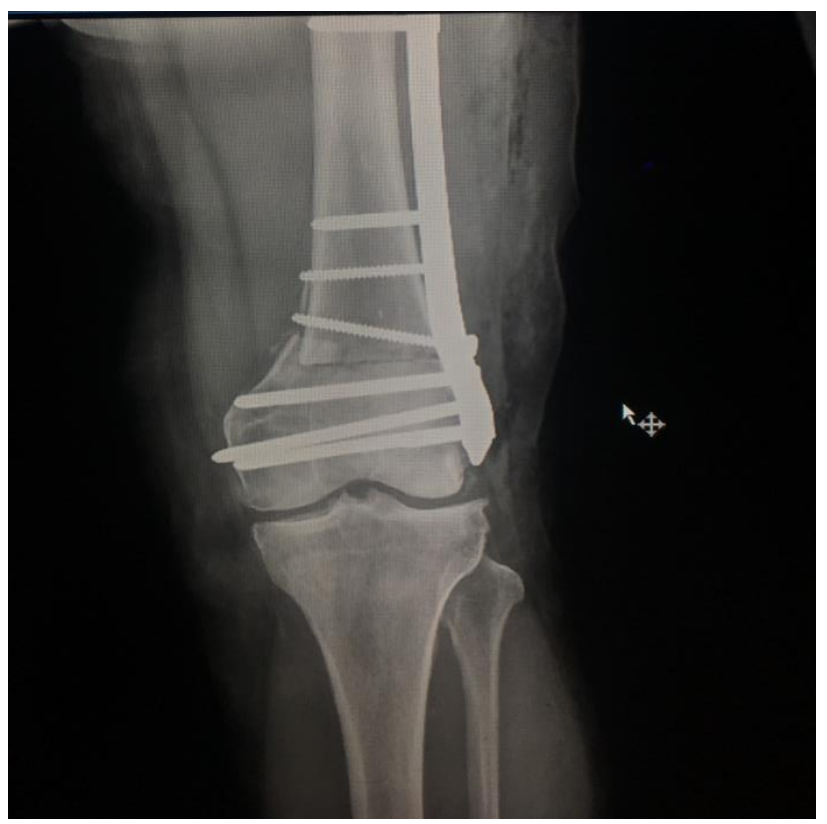

Figure 3 Post-operative radiography. Varus left femur osteotomy showing the correct alignment of the operated axis of the knee and the increase in the medial joint space

The rehabilitation plan (Fig. 4) consisted of 4 months of work with 2 to 3 sessions of home physical therapy per week.
In early postoperative rehabilitation, it was considered to prioritize mobility, with the aim of avoiding adhesions and keeping blood circulation active. Rehabilitation consisted of active and active mobilization exercises, passive kneecap mobilizations, quadriceps toning, progressive re-education of gait and control of pain, inflammation and edema with the use of physical agents.

\section{Rehabilitation model}

\begin{tabular}{|c|c|c|c|}
\hline $\begin{array}{l}\text { 1st phase } \\
\text { (1- } 7 \text { days } \\
\text { after } \\
\text { surgery) }\end{array}$ & $\begin{array}{l}\text { 2nd phase } \\
\text { (1- week- } 1 \\
\text { month after } \\
\text { surgery) }\end{array}$ & $\begin{array}{l}\text { 3rd phase } \\
\text { (1 month- } 3 \\
\text { months) }\end{array}$ & $\begin{array}{l}\text { 4th phase } \\
\text { ( } 3 \text { months- } 4 \\
\text { months) }\end{array}$ \\
\hline $\begin{array}{l}\text { Immediate } \\
\text { post- } \\
\text { operative } \\
1 . \\
\text { Cryotherap } \\
\text { y. } \\
1.1 \quad 30 \\
\text { minutes } 3 \\
\text { times a day. } \\
2 . \quad \text { Inelastic } \\
\text { compressio } \\
n \text { bandage } \\
\text { on the } \\
\text { affected } \\
\text { limb. } \\
2.1 \text { Change } \\
\text { of bandage } \\
\text { the morning } \\
\text { after } \\
\text { surgery. } \\
2.2 \text { Thrombotic } \\
\text { Throm } \\
\text { surveillance } \\
\text { 3. Assisted } \\
\text { continuous } \\
\text { and active } \\
\text { passive } \\
\text { mobilizatio } \\
\text { n. } \\
3.1 \text { n sets of } \\
10 \text { passive } \\
\text { repetitions } \\
\text { in knee } \\
\text { flexion and } \\
\text { extension. } \\
3.2 \text { Active } \\
\text { mobilizatio } \\
n \text { of healthy } \\
\text { joints (hip } \\
\text { flexion }\end{array}$ & $\begin{array}{l}\text { Early post- } \\
\text { operative. } \\
\text { 1. Surgical } \\
\text { wound } \\
\text { healing every } \\
\text { 3rd day. } \\
1.1 \text { Healing } \\
\text { with } \\
\text { microdacyne } \\
\text { and dressing } \\
\text { change. } \\
2 . \quad \\
\text { Cryotherapy. } \\
2.2 \\
\text { minutes } 15 \\
\text { times a day. } \\
3 . \quad \text { Inelastic } \\
\text { compression } \\
\text { bandage of } \\
\text { the affected } \\
\text { limb } \\
\text { control to } \\
\text { inflammation } \\
\text { and edema. } \\
4 . \quad \text { Assisted } \\
\text { active } \\
\text { mobilization. } \\
4.1 \mathrm{~N} \text { series } \\
\text { of } 10 \text { active } \\
\text { repetitions in } \\
\text { knee flexion } \\
\text { and } \\
\text { extension. } \\
5 . \quad \text { Muscle } \\
\text { toning. } \\
5.1 \text { Isometric } \\
\text { contractions } \\
\text { in the lower } \\
\text { left limb. N } \\
\text { series with N }\end{array}$ & $\begin{array}{l}\text { Orthopedic } \\
\text { rehabilitatio } \\
\text { n. } \\
1 \text {. Active } \\
\text { mobilization } \\
\text { of the } \\
\text { affected limb. } \\
1.1 \text { Use of } \\
\text { static } \\
\text { pedalboard } \\
\text { with th } \\
\text { tolerance } \\
\text { duty cycles } \\
\text { using the } \\
\text { Borg test. } \\
2 . \\
\text { Strengthenin } \\
\text { g of the } \\
\text { operated limb } \\
\text { with } \\
\text { progressive } \\
\text { resistance } \\
\text { exercises } \\
\text { using the } \\
\text { Troiser test. } \\
2.1 \text { Changes } \\
\text { should be } \\
\text { shown in the } \\
\text { first } 8 \text { weeks. } \\
2.2 \text { pull } \\
\text { permanent } \\
\text { changes in } \\
\text { the } 16 \text { weeks } \\
\text { of treatment. } \\
3 . \\
\text { support on } \\
\text { the operated } \\
\text { limb, weight } \\
\text { distribution } \\
\text { between both } \\
\text { lower limbs }\end{array}$ & $\begin{array}{l}\text { Reintegration } \\
\text { to activities. } \\
1 . \quad \text { Muscular } \\
\text { strengthening } \\
\text { of the } \\
\text { operated limb. } \\
1.1 \text { Same } \\
\text { handling with } \\
\text { progressive } \\
\text { resistance. } \\
2 . \quad 5 \\
\text { Reincorporati } \\
\text { on to work } \\
\text { activities. } \\
2.1 . \text { Training } \\
\text { based on your } \\
\text { work for } \\
\text { activities. } \\
3 . \quad \text { Tasks } \\
\text { assigned for } \\
\text { discharge. } \\
3.1 \quad \text { Weight } \\
\text { reduction with } \\
\text { static pedal } \\
\text { exercise for } \\
20 \text { minutes. } \\
3.2 \text { General } \\
\text { strengthening } \\
\text { with } \\
\text { resistance } \\
\text { leagues. } \\
\text { days of } \\
\text { training using } \\
1 \text { or } 2 \text { muscle } \\
\text { groups per } \\
\text { day. } \\
\text { to. } 3 \text { sets of } 15 \\
\text { repetitions. } \\
\text { b. } 3 \text { exercises } \\
\text { per muscle }\end{array}$ \\
\hline
\end{tabular}

PÉREZ-ÁNGELES, José Manuel. Rehabilitation in left distal femoral varus osteotomy and left knee arthroscopy by gonarthrosis grade III: 4 phase model. About a case. Journal of Technological Prototypes. 2020 


\begin{tabular}{|c|c|c|c|}
\hline $\begin{array}{l}\text { extension, } \\
\text { abduction } \\
\text { and } \\
\text { adduction). } \\
3.3 \text { Assisted } \\
\text { active } \\
\text { mobilizatio } \\
n \text { in knee } \\
\text { flexion and } \\
\text { extension. } \\
4 \text {. Left } \\
\text { ankle } \\
\text { pumping } \\
\text { exercise. } \\
4.1 \quad \text { Slow } \\
\text { active } \\
\text { mobilizatio } \\
n 5 \text { minutes. } \\
5 \text {. Anti- } \\
\text { inflammator } \\
y \\
\text { cryotherapy } \\
\text { at the end of } \\
\text { the exercise. } \\
\quad 5.1 \quad 30\end{array}$ & $\begin{array}{l}6 . \\
\text { Proprioceptio } \\
\text { n. } \\
6.1 \quad \text { Partial } \\
\text { weight } \\
\text { unloading in } \\
\text { the operated } \\
\text { lower limb. } \\
6.2 \text { Discharge } \\
\text { under pain } \\
\text { threshold. } \\
6.3 \\
\text { Download } \\
10 \% \\
\text { weight bovery } \\
3 \text { days. } \\
7 . \\
\text { Progressive } \\
\text { resistance } \\
\text { exercises on } \\
\text { healthy } \\
\text { limbs. } \\
7.1 \quad \text { Use of } \\
\text { yellow } \\
\text { resistance } \\
\text { league with } \mathrm{N} \\
\text { series of N } \\
\text { repetitions. } \\
7.2 \quad \text { Make } \\
\text { progression } 3 \\
\text { weeks. } \\
8 . \text { Interferenti } \\
\text { al current in } \\
\text { knee joint } 0.3 \\
\text { Hz } \\
\text { alternating } \\
\text { mode } \\
\text { minutes. }\end{array}$ & \begin{tabular}{l} 
4. Tolerance \\
squat with \\
support on \\
rails. \\
5. \\
Proprioceptio \\
n and \\
reeducation \\
of gait. \\
$5.1 \quad$ Support \\
on stable \\
surfaces. \\
5.2 Up and \\
down stairs. \\
\multicolumn{2}{c}{5.3 walk } \\
on stable \\
and \\
unstable \\
surfaces.
\end{tabular} & $\begin{array}{l}\text { 4. Follow-up } \\
\text { every } \\
\text { months to } \\
\text { reassess the } \\
\text { functionality } \\
\text { of the patient. }\end{array}$ \\
\hline
\end{tabular}

Table 1 Rehabilitation model used in a post-operative arthroscopy left knee and varus left femur osteotomy patient.

Source: table prepared by the author

At 2 months (Figure 4) and 4 months (Figure 5) of the intervention, an appointment was taken in an outpatient orthopedic clinic and radiographic control, where bone consolidation was observed, with no evidence of loosening and correct limb alignment.

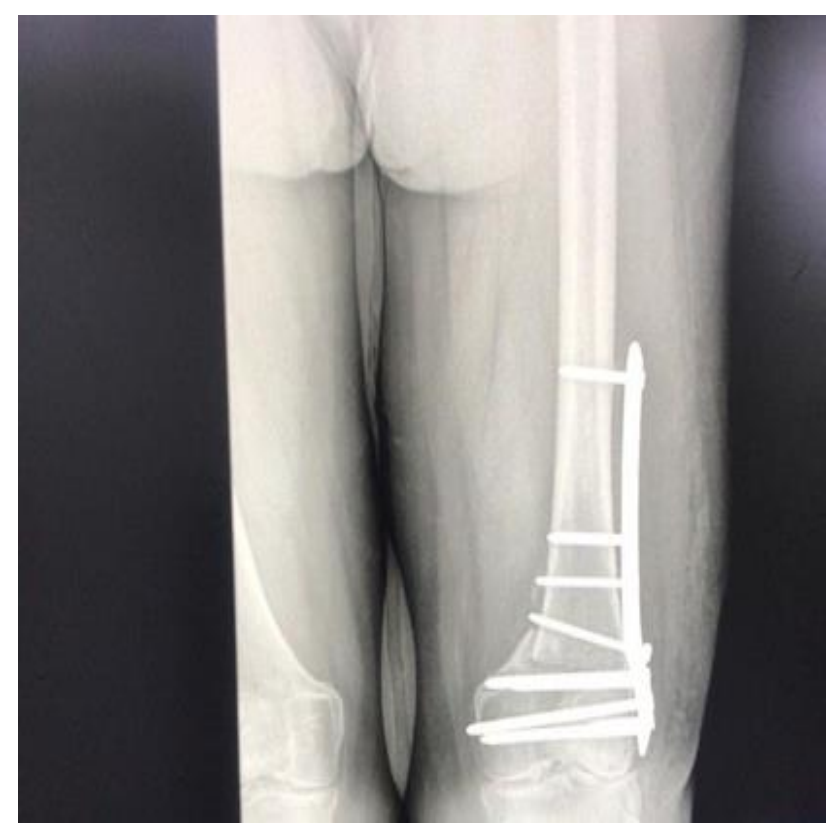

Figure 4 Control radiograph 2 months after surgery. The formation of the bone callus in the osteotomy line is appreciated.

After 4 months of intervention and rehabilitation, the patient does not report pain, she has a range of motion in knee flexion that goes from $0^{\circ}-115^{\circ}$ and a good muscular trophism, currently she walks with a 1-point cane due to right degree gonarthrosis II. The management of this patient must be individualized. The results of the treatment have been effective, the evolution was satisfactory with total independence in their activities of daily life. According to the clinical case presented, the rehabilitative management of this patient is demanding and there is no international bibliography. 


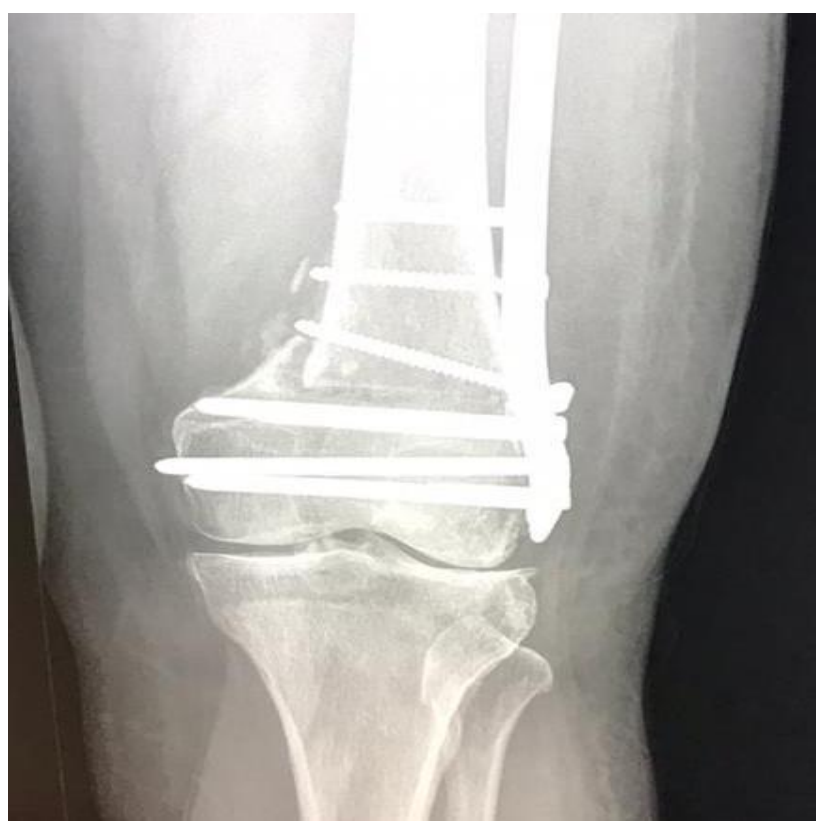

Figure 5 Control radiograph 4 months after surgery. Bone remodeling and consolidation in the osteotomy line can be seen

\section{Discussion}

In the case that is presented, the patient had pain on active mobility of $90^{\circ}$ in flexion, with valgus deformity of the knee, with poor gait, and motor deficit, for which reason she was tributary to left knee arthroscopy and varus left distal femur.

The initial approach was to perform a total knee arthroplasty, since it offers more stability and favors a functional recovery, as well as a faster rehabilitation.

The age of this patient was the cause that changed the approach strategy, proposing to perform in a single surgical act the 2 techniques; arthroscopy knee, and varus osteotomy distal femur.
Since this is a case not previously described, there was no bibliography to decide on a specific rehabilitation program, so the approach and preparation of the program was purely theoretical. Performing both procedures at the same time involved greater surgical aggression, but it involves a single surgical and rehabilitation process, and this reduced recovery time.

Another factor to take into account is the risk of infection, since it was high in this patient given its characteristics (obesity and probable diabetes).

The rehabilitation model was structured with the following objectives:

1. Decreased symptoms after varus osteotomy surgery and left knee arthroscopy.

2. Improvement of patient functionality.

3. Decreased recovery time.

4. Reintegration to activities of daily living.

In order to comply with the treatment objectives, emphasizing the recovery phases and the recovery stages, the 4 recovery phases were:

1. Immediate post-operative treatment.

2. Late post-operative treatment.

3. Orthopedic rehabilitation.

4. Reintegration to activities.

Objectives phase 1: immediate post-operative treatment.

I. Cryotherapy: 30 minutes of application 3 times a day.

II. Inelastic compression bandage for the operated limb: this compression reaches pressures of up to $45 \mathrm{mmHg}$ at rest. 
III. Active Twin Pumping Exercises: Active movement in plant flexing and dorsiflexing reaches pressures up to $95 \mathrm{mmHg}$, making pumping efficient.

IV. Initial mobility: passive-continuous and active knee-assisted mobilization below the pain threshold, kneecap mobilization. Active mobilization of the rest of the body segments.

V. Walk with assistant: 4-point walker.

Total number of hospital sessions: 2 (cryotherapy only as a physical agent).

Progression criteria:

- Pain on an analog visual scale of 8 or less.

- Functional mobility arches:

i. Extension $-10^{\circ}$

ii. $\quad 30^{\circ}$ flexion

- Edema and minimal heat.

treatment.

Phase 2 objectives: Late post-operative

I. Healing and care of the surgical wound. Dressings change every third day and withdrawal of the points in 15 days.

II. Inelastic compression bandage for the operated limb: $40 \mathrm{mmHg}$ at rest.

III. Active twin pumping exercises: Active movement in plant flexion and dorsiflexion reaches pressures of up to $95 \mathrm{mmHg}$ making efficient pumping.

IV. Full-range mobility: assisted active mobilization below the pain threshold.

V. Strengthening: isometric resisted in the operated limb. Number of series and repetitions to tolerance. Maximum isometric exercises in extension to fix the kneecap.
VI. Proprioception: partial discharge of weight on the operated limb, below the pain threshold. $10 \%$ of body weight every 3 days.

VII. General strengthening: progressive resistance exercises in healthy extremities, use of resistance leagues, series and repetitions to tolerance.

VIII. Pain management: Interferential current in knee joint $0.3 \mathrm{~Hz}$ alternating mode 15 minutes. Cryotherapy 15 minutes 2 times a day.

Total number of home sessions: 20 .

Progression criteria:

- Pain on an analog visual scale of 6 or less.

- Increased mobility:

i. $\quad$ Flexion $\square 80^{\circ}$

ii. Extension $-10^{\circ}$ to $0^{\circ}$

- Minimum force:

i. Daniels 3 limb operated.

ii. Daniels 4 rest of body segments.

Phase 3 objectives: Orthopedic rehabilitation.

I. Active mobilization of the operated limb: use of a pedal for rehabilitation with work cycles based on the Borg test.

II. Specific strengthening of the operated limb with progressive resistance exercises using the Troiser program. 8 The objective of this muscle strengthening program is to improve the active stability and function of the injured knee.

a. Changes should show in the first 8 weeks:

PÉREZ-ÁNGELES, José Manuel. Rehabilitation in left distal femoral varus osteotomy and left knee arthroscopy by gonarthrosis grade III: 4 phase model. About a case. Journal of Technological Prototypes. 2020 
i. Improving the timing of motor units.

ii. Improving coordination and muscle activation.

iii. Increased frequency of motor unit discharge.

iv. Decreased activation of antagonist muscles.

b. At the end of 16 weeks, it should show:

i. Increased muscle volume as a consequence of increased strength.

ii. Increased muscle contractile material.

c. Expected results in the training program:

i. Increased static muscle strength.

ii. Hypertrophy.

iii. Maximum muscle strength.

iv. Activation of anaerobic systems, improving the extraction of $\mathrm{O}^{2}$ from myoglobin.

\section{Muscle strength work protocols obtained from NSCA.}

\begin{tabular}{|l|l}
\hline Troisier Static Work & Hettinger \& Muller \\
\hline
\end{tabular}

- Direct or indirect load.

- Basal load: 50\% Maximum static force.

- Development: contractions until exhaustion.

- $\quad$ Rest: 6 seconds with 6 rest.

- Direct load.

- Basal load: 33$50 \%$ Maximum static force.

- $1 / 3$ daily contractions.

- Rest: 2-6 seconds of contraction with 2-6 seconds of rest.

Table 2 Comparison of 2 muscle strength work protocols obtained from the National Strenght and Conditioning Association

Source: Table prepared by the author
III. Full support with distribution of loads between lower limbs: this patient had her instrument for gait walking changed for a 4-point cane, starting with gait training on household surfaces, so that this helps to a faster rehabilitation of the environment.

IV. Tolerance squat: using handrails from her home to support herself, she was asked to squat below the pain threshold, with the passage of the sessions, the patient managed to perform the full squat.

V. Proprioception and gait re-education: use of stable and unstable surfaces such as pillows and sponge bases. His march was performed on home stages, as well as going up and down stairs.

Total number of home sessions: 30

Progression criteria:

- Pain on an analog visual scale of 3 or less.

- Increased mobility:

i. Flexion $\square 100^{\circ}$

ii. Extension $0^{\circ}$

- Minimum force:

i. Daniels $\square 4$ operated limb.

ii. Daniels 5 rest of body segments.

Objectives phase 4: Reintegration to activities.

a) Muscular strengthening of the operated limb: same management with progressive resistance.

b) Training based on their activities: they re-educate and guide the patient in reintegration into their home and work activities, adapting some activities and improving their ergonomics.

PÉREZ-ÁNGELES, José Manuel. Rehabilitation in left distal femoral varus osteotomy and left knee arthroscopy by gonarthrosis grade III: 4 phase model. About a case. Journal of Technological Prototypes. 2020 
c) Tasks assigned for discharge:

i. Weight reduction and control: follow-up with a nutritionist, in addition to a pedal aerobic exercise program, in 20-minute cycles.

ii. Muscle strengthening: following a strength training program, with series of 15 repetitions, training 1 to 2 muscle groups per day.

iii. Follow-up of the patient: every 2 months a visit is scheduled to assess the evolution, and verify if a reoperation is necessary.

Total number of home sessions: 15 .

Discharge criteria:

- Increased patient's perception of safety when walking on unstable or unfamiliar terrain and using stairs.

- Improvement in balance between both sides in strength, measured by the Daniels scale.

- Increase in equilibrium, measured by the Tinneti and Berg balance scales.

These findings were clinical without having carried out any analysis in this regard. The factors that are considered fundamental are the education of the patient about the importance of a rehabilitation, the perseverance to follow his sessions, and later his physical care.

\section{Methodology}

We present a clinical case of a 47-year-old female patient with no significant history presenting her current long-term condition with predominance of pain in the left knee, postarthroscopy surgery and varus osteotomy of left distal femur, beginning her physical rehabilitation the day after surgery, with satisfactory results.

The combination of both surgical procedures in the same act, makes a functional recovery earlier and more effective, than if it had been operated in 2 times.

\section{Results}

The main results obtained qualitatively with this rehabilitation program have been the following:

1. Reduction of recovery time from 7 months on average to 4 months.

2. Increased patient's perception of safety when walking on unstable terrain and using

stairs.

3. Improvement of balance and strength between both sides, measured by Daniels scale.

The factors that have been considered to achieve adherence to this program are patient education on the importance of rehabilitation, the consistency of following rehabilitation at home and the availability of material resources.

\section{Conclusions}

The interventions of how and when to intervene in this pathology are not established. 
After the review, poor prognostic factors include established gonarthrosis, lack of therapist-patient work involving reciprocal depression, and obesity. Age, sex, and surgical techniques have not been obstacles to the excellent results. In this case, a combined therapy was used that forced an early mobilization of the knee and muscular strengthening with progressive loading that allowed us a faster recovery and a reintegration to activities.

The evaluation of the results has been based on the subjective sensation of the patient with the influence that pain has on the state of mind, and on the consideration of the results. It seems to be the most appropriate, despite the low objectivity of this assessment.

\section{Ethical responsibilities}

Protection of people and animals. The author declares that no human or animal experiments have been performed for this research.

Confidentiality of data. The author declares that he has followed the protocols on the publication of patient data.

Right to privacy and informed consent. The author has obtained the informed consent of the patient referred to in this article. The document is in the possession of the corresponding author.

\section{References}

[1] A. Esrafilian A, Taghi Karimi M, Eshraghi A: Design and evaluation of a new type of knee orthosis to align the mediolateral angle of the knee joint with osteoarthritis. Advances in Orthop. 2012, ID 104927.
[2] B. National Institute for Health and Clinical Excellence. Osteoarthritis: national clinical guideline for care and management in adults. London: NICE; 2008. Disponible en: www.nice.org.uk/CG059.

[3] C. Hochberg MC, Altman R, Brandt K, Clark B, Dieppe P, eGriffin M, et al. Guidelines for the medical managment of ostearthritis. Arthritis and Rheumatism 1995; 38: 1.541-6.

[4] D. Fernandes L, Hagen KB, Bijlsma JWJ, Andreassen $\mathrm{O}$, Christensen $\mathrm{P}$, Conaghan $\mathrm{PG}$, et al. EULAR recommendations for the non-pharmacological core Management of hip and knee osteoartritis. Ann Rheum Dis. 2013;72:1125-35.

[5] E. Brady T. Strategies to support selfmanagement in osteoarthritis: five categories of interventions, including education. Orthop Nurs. 2012;31:124-30.

[6] F. Kanamiya T, Naito M, Hara M, Yoshimura I. The influences of biomechanical factors on cartilage regeneration after tibial osteotomy for knees with medial compartment osteoarthritis: clinical and arthroscopic observations. Arthroscopy. 2002 ; 18 (7): 725-9.

[7] G. Guía de Práctica Clínica (2012) tratamiento con artroplastía de rodilla en pacientes mayores de 60 años. Secretaria de Salud de México. 